\title{
Tide and habitat features affect salt marsh songbird nest survival in northeast Florida, USA
}

\author{
W. Andrew Cox ${ }^{1, *}$, Amy C. Schwarzer ${ }^{1}$, Brett Tornwall ${ }^{1,2}$, Roxan Chicalo ${ }^{1,3}$ \\ ${ }^{1}$ Fish and Wildlife Research Institute, Florida Fish and Wildlife Conservation Commission, Gainesville, Florida 32601, USA \\ ${ }^{2}$ Present address: Children's Oncology and Department of Biostatistics, Colleges of Medicine, Public Health, \\ and Health Professions, University of Florida, Gainesville, Florida 32607, USA \\ ${ }^{3}$ Present address: Department of Integrative Biology, University of Guelph, 50 Stone Road, Guelph, Ontario N1G 2W1, Canada
}

\begin{abstract}
Tidal salt marshes face numerous pressures that threaten their ecological integrity, and many salt marsh vertebrates have exhibited declines concomitant with the degradation of salt marsh habitats. We studied nest survival of MacGillivray's seaside sparrow Ammospiza maritima macgillivraii and Worthington's marsh wren Cistothorus palustris griseus in smooth cordgrass Spartina alterniflora and black needlerush Juncus roemerianus dominated salt marshes in northeast Florida, USA, during 2015-2017 to understand why both species have undergone range contractions. We evaluated the effects of tides, habitat features, and weather on nest survival. The probability of a nest surviving from laying to fledging young was low for both species (seaside sparrow: $0.03,95 \%$ CI: $0.00,0.10$; marsh wren: $0.10,95 \%$ CI: $0.04,0.18)$, suggesting that nest survival may limit population growth. The most substantial threat to marsh wren and seaside sparrow nest survival was from greater than normal high tides. However, there was limited evidence of direct nest loss due to flooding. An analysis of only fledged and depredated nests suggests that higher tides influenced nest survival by increasing nest predation, substantially so for marsh wrens. Other factors negatively associated with marsh wren nest survival, albeit less strongly, included precipitation and the amount of black needlerush at and within $50 \mathrm{~m}$ of the nest. The effect of tide height on nest survival suggests that salt marsh birds in northeast Florida are vulnerable to continued sea-level rise, which is exacerbated by upland development that will hinder marsh migration. Monitoring and protecting northeast Florida's high-elevation, cordgrass-dominated marshes should be a priority.
\end{abstract}

KEY WORDS: Marsh wren - Cistothorus palustris - Seaside sparrow - Ammospiza maritima · Nest survival $\cdot$ Sea-level rise $\cdot$ Climate change $\cdot$ Demography

\section{INTRODUCTION}

Tidal salt marshes face a variety of pressures that threaten their ecological integrity at local and global scales. For example, coastal development has directly and indirectly reduced the quality and quantity of salt marsh habitat via ditching, diking, impounding, and dredging (Greenberg et al. 2006). In addition, the alteration of tidal marsh habitat via intrusion by coldintolerant species such as mangroves (Williams et al. 2014) has increased because of increased global temperatures (Cavanaugh et al. 2014). Furthermore, sea-

\footnotetext{
${ }^{*}$ Corresponding author: andrew.cox@myfwc.com
}

level rise associated with climate change has been implicated in the conversion of high-marsh habitat to low-marsh habitat, and in some areas the loss of all salt marsh habitat (Donnelly \& Bertness 2001). Increased salt marsh elevation via sediment accretion and upland migration may be sufficient to outpace sea-level rise, but whether it occurs is dependent on marsh-specific characteristics (Morris et al. 2002) and is substantially less likely in highly developed areas with hardened coastlines (Kirwan et al. 2016).

Florida has ca. $1790 \mathrm{~km}^{2}$ of salt marsh (FFWCC 2012), which represents $>10 \%$ of the salt marshes

() The authors 2020. Open Access under Creative Commons by Attribution Licence. Use, distribution and reproduction are unrestricted. Authors and original publication must be credited. 
found in the USA (Greenberg \& Maldonado 2006). The State of Florida considers its salt marsh to be in 'poor and declining' condition due in large part to the threats described above and has identified salt marsh as one of the most threatened habitats in the state (FFWCC 2012). Unsurprisingly, as this habitat has declined, so have the populations of many obligate salt marsh vertebrates (FFWCC 2016). Among birds, the state lists as threatened 2 subspecies of marsh wren (Cistothorus palustris mariannae and C. p. griseus) and 2 subspecies of the seaside sparrow (Ammospiza maritima peninsulae and A. m. juncicola) (FFWCC 2016); a third subspecies of seaside sparrow (A. m. macgillivraii) was recently evaluated for federal listing (USFWS 2018). Identification of factors that contribute to these declines and implementation of management actions that benefit the species are priorities for the state (FFWCC 2016).

We studied nest survival of MacGillivray's seaside sparrow A. m. macgillivraii (hereafter 'sparrow') and Worthington's marsh wren C. p. griseus (hereafter 'wren') at 7 smooth cordgrass Spartina alterniflora (hereafter 'cordgrass') and black needlerush Juncus roemerianus (hereafter 'needlerush') dominated salt marsh sites in northeast Florida during 2015-2017. Seaside sparrows occur in salt marsh along the Gulf Coast and on the Atlantic Coast from Florida to
Maine, with MacGillivray's sparrows restricted to salt marshes from North Carolina to Florida (Post \& Greenlaw 2018). Wrens occur in fresh water and salt marshes throughout much of North America, with Worthington's marsh wren restricted to coastal salt marshes from South Carolina to Florida (Kroodsma \& Verner 2013). The range of both species in Florida has contracted by $80 \%$ of their historic extents (Kale $1996 a, b)$, and their occurrence is now limited to the 2 northeastern-most counties in the State. Florida populations of both subspecies have rarely been studied, and habitat relationships fundamental to managing them successfully are unknown. We focused on nest survival (the probability that a nest will fledge young), because this is the primary reproductive constraint on passerine birds (Martin 1992) and can be an important driver of population declines (e.g. Donovan \& Thompson 2001, Fletcher et al. 2006).

We assessed 4 hypotheses (summarized in Table 1) that might explain the variation in nest survival rates, which in salt marshes is primarily a function of flooding and nest predation (Kale 1965, Greenberg et al. 2006, Bayard \& Elphick 2011). Our first hypothesis was that tide height would influence nest survival (Bayard \& Elphick 2011, Hunter 2017). We predicted that greater than normal high tides would reduce nest survival, but that higher-elevation nests would

Table 1. Model structure and model selection results for a priori candidate models describing variation in nest survival of marsh wrens and seaside sparrows in northeast Florida, USA, during 2015-2017. Models for each species also include the temporal covariates (nest stage and year for wrens, nest stage for sparrows) that influenced nest survival. The best stepwise model for each species is included in the table but not in the model selection analysis because it was not an a priori model. AIC ${ }_{\mathrm{c}}$ : Akaike's information criterion corrected for small sample sizes; $K$ : number of parameters in the model ${ }_{i} w_{i}$ : weigth of evidence supporting the model

\begin{tabular}{|c|c|c|c|c|c|}
\hline Name & Model structure & $K$ & $\mathrm{AIC}_{\mathrm{C}}$ & $\Delta \mathrm{AIC}_{\mathrm{C}}$ & $W_{\mathrm{i}}$ \\
\hline \multicolumn{6}{|l|}{ Marsh wren } \\
\hline Flood avoidance & Elevation + Nest height + Max high tide & 8 & 1756.9 & 0.0 & 1.0 \\
\hline Predation (patch scale) & Patch tall cordgrass + Patch needlerush + Distance to edge & 8 & 1818.5 & 61.6 & 0.0 \\
\hline Predation (nest scale) & $\begin{array}{l}\text { Nest veg height }+ \text { Nest veg density }+ \text { Tall cordgrass }+ \text { Short cordgrass } \\
+ \text { Needlerush }+ \text { Mean concealment }\end{array}$ & 11 & 1824.4 & 67.5 & 0.0 \\
\hline Weather & Precipitation & 6 & 1828.6 & 71.7 & 0.0 \\
\hline Null & & 5 & 1839.9 & 83.0 & 0.0 \\
\hline Stepwise best & $\begin{array}{l}\text { Elevation + Max high tide + Precipitation + Patch short cordgrass } \\
+ \text { Patch needlerush }+ \text { Nest needlerush }+ \text { Mean concealment }\end{array}$ & 12 & 1753.4 & & \\
\hline \multicolumn{6}{|l|}{ Seaside sparrow } \\
\hline Flood avoidance & Elevation + Nest height + Max high tide & 6 & 348.0 & 0.0 & 1.0 \\
\hline Null & & 3 & 361.9 & 13.9 & 0.0 \\
\hline Weather & Precipitation & 4 & 362.2 & 14.2 & 0.0 \\
\hline Predation (nest scale) & $\begin{array}{l}\text { Nest veg height }+ \text { Nest veg density }+ \text { Tall cordgrass }+ \text { Short cordgrass } \\
+ \text { Needlerush }\end{array}$ & 8 & 363.7 & 15.7 & 0.0 \\
\hline Predation (patch scale) & Patch tall cordgrass + Patch needlerush + Distance to edge & 6 & 365.2 & 17.2 & 0.0 \\
\hline Stepwise best & Nest height + Max high tide & 5 & 346.1 & & \\
\hline
\end{tabular}


be associated with greater survival because they would be less prone to tidal flooding (Greenberg et al. 2006, Hunter 2017). We also predicted that the effect of tides on nest survival would not be influenced by the height of a nest within the vegetation for sparrows because previous work suggests that higher sparrow nests are at a reduced risk of flooding but are more vulnerable to predation (Bayard \& Elphick 2011, Hunter 2017). By contrast, we predicted that nest height would be positively associated with wren nest survival because their closed-dome nests might ameliorate any increase in predation risk from visually oriented predators.

Our second hypothesis was that that patch- and landscape-level characteristics would influence nest survival. We predicted that nest survival would be greater farther from upland edges because wrens and sparrows avoid upland edges (Nuse et al. 2015, Hunter et al. 2017, A. Schwarzer unpubl. data). We further predicted that nests in patches with more cordgrass and less needlerush would have greater nest survival (as observed by Kern et al. 2012), because marsh rice rats Oryzomys palustris, potentially a dominant nest predator in salt marshes (Kale 1965, Post et al. 1983, R. Chicalo pers. obs.) prefer needlerush-dominated habitats over cordgrass-dominated habitats (Post 1981).

Our third hypothesis was that the type of vegetation at the nest site would influence nest survival. We predicted that taller, denser vegetation and better concealed nests (Borgmann \& Conway 2015) would reduce encounters with predators and thus increase rates of nest survival.

Our final hypothesis was that the heavy precipitation events common during spring and summer in Florida would influence nest survival. We predicted that heavy rain and associated winds would lead to increased rates of nest failure.

\section{MATERIALS AND METHODS}

\subsection{Study area and species}

We found and monitored wren and sparrow nests at 7 sites on the Nassau River and Clapboard Creek in Duval and Nassau Counties in northeast Florida, just south of the Georgia border (Fig. 1). Four of the sites were in the Timucuan Ecological and Historic Preserve and the remaining 3 were on private property north of the preserve. The uplands surrounding the sites were a combination of preserved land, housing, and industry. The climate of northeast Florida is more temperate than that of peninsular Florida but is

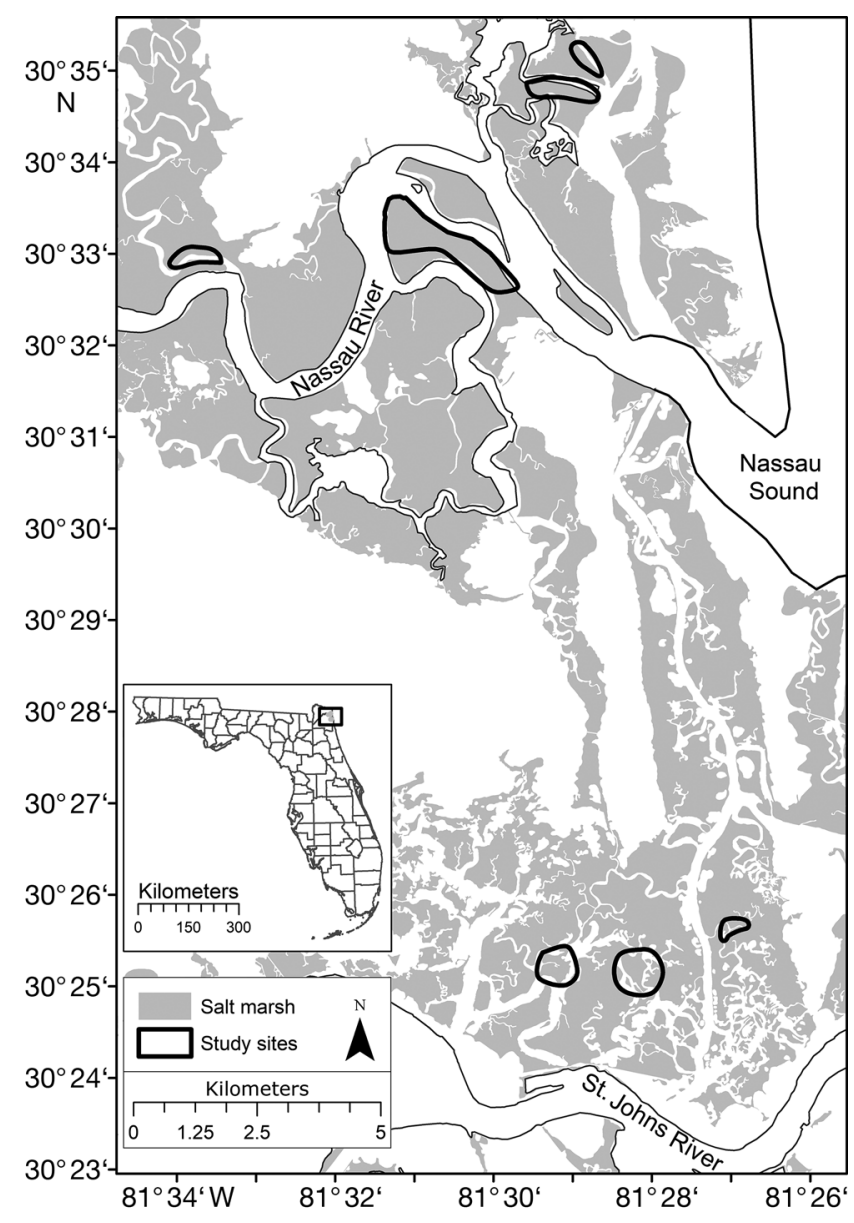

Fig. 1. Location of 7 sites in a study of marsh wren and seaside sparrow nest survival in northeast Florida, USA, during 2015-2017

still characterized by hot, humid summers, substantial late spring and summer rainfall, and mild winters, with temperatures infrequently dropping below freezing. The average tidal range in northeast Florida is $0-1.5 \mathrm{~m}$, with tides $>2 \mathrm{~m}$ during spring (i.e. king) tides. The tidal cycle is approximately $29 \mathrm{~d}$, with 2 low and 2 high tides per day.

We selected sites with variable wren and sparrow densities (A. Schwarzer unpubl. data) to sample nests from a presumed gradient of habitat quality. Five of 7 sites were dominated by cordgrass, which exhibited a sharp transition in height from $\geq 1 \mathrm{~m}$ (tall cordgrass) within several meters of a creek or river to $<50 \mathrm{~cm}$ (short cordgrass) in the lower-elevation flats that composed much of the marsh. The 2 southwesternmost sites were dominated by needlerush, with small amounts of cordgrass interspersed throughout. All sites had smaller patches of succulents such as glasswort Salicornia depressa and saltwort Batis maritima, as well as sea oxeye Borrichia frutescens. 
Marsh wrens build domed nests and usually build multiple dummy nests, which may indicate a highquality territory (Verner \& Engelsen 1970), deter predators (Leonard \& Picman 1987), or provide shelter for newly fledged young (Chicalo et al. 2019). Wren nesting territories were usually quite small (82-155 $\mathrm{m}^{2}$; Kale 1965) and were densely packed along the edges of the river and tidal creeks where the cordgrass was tallest. Sparrows build open-cup nests and also nested near creeks, but nest sites tended to be in shorter vegetation along the edges of succulent patches. Neither species was observed nesting in short cordgrass in the low-elevation flats.

\subsection{Field methods and habitat measurements}

We found and monitored nests using established protocols (Martin \& Geupel 1993) from early April to mid-August during 2015-2017. We used iButton ${ }^{\circledR}$ (Thermocron) temperature loggers in most nests (wren, $\mathrm{n}=729$ of 888 nests [82\%]; sparrow, $\mathrm{n}=92$ of 116 nests [79\%]), because temperature data provided precise nest completion dates and times (Sutti \& Strong 2014) and allowed us to check nests less frequently (every $7 \mathrm{~d}$ ) than is typically suggested for passerines (2-4 $d_{i}$ Martin \& Geupel 1993) to reduce disturbance to vegetation and nesting birds. We determined completion dates by comparing temperatures in nests with ambient temperatures recorded by a control logger in a nearby abandoned sparrow nest or a wren dummy nest (nest and ambient temperatures differed until a nest failed or fledged). We performed nest checks at nests without loggers every $7 \mathrm{~d}$. We used a combination of temperature logger data, nestling ages, and indicators of successful fledging (e.g. aggressive parental behavior, presence of fecal matter at the rim of the nest) to determine if a nest fledged young. We recorded a nest as depredated if there was obvious physical evidence (e.g. broken egg shells, tracks, nests shredded or punctured from the top) or if temperature logger data indicated that the time of failure did not fall within $1.5 \mathrm{~h}$ of a high tide. A nest was classified as flooded if there was physical evidence (e.g. wet nest with cold or missing eggs) or if temperature logger data indicated that the time of failure fell within $1.5 \mathrm{~h}$ of a high tide. Nests with inconclusive or missing physical evidence or temperature logger data were classified as failed for unknown causes.

We recorded a nest's location upon its discovery using a handheld GPS and measured nest height (to the nearest $\mathrm{cm}$ ) and average vegetation height (to the nearest $5 \mathrm{~cm}$ ) at the nest. We recorded date, time, number of eggs and/or nestlings present, and approximate age of any nestlings at all nest checks. We measured vegetation at all sparrow nests that we could relocate following failure (some disappeared following high tides). We measured vegetation at a subset of the wren nests within each territory because the vegetation measurements of adjacent nests, which were usually just a few meters apart, often overlapped. Our selection of wren nests for vegetation measurement was nonrandom, but we selected at least 1 nest per territory, measured nest vegetation throughout the season to avoid potential temporal biases, and avoided measuring vegetation at nests that had fallen or were substantially degraded. We measured nest-scale vegetation density by counting the stems in a $1 \mathrm{~m}^{2}$ quadrat around each nest and estimated the proportion of the quadrat composed of needlerush, tall cordgrass, and short cordgrass. We also visually estimated the proportion of habitat at the patch scale (defined as a $50 \mathrm{~m}$ radius from the nest) that was tall cordgrass, short cordgrass, and needlerush by averaging qualitative estimates in $5 \%$ increments for each of 4 quarters of the circle. Finally, we estimated overall nest concealment by averaging visual estimates of concealment taken $1 \mathrm{~m}$ from the nest in each of 4 directions (creek-side, landward, upstream, and downstream).

We obtained tide data from the National Oceanic and Atmospheric Administration (NOAA) tide station 8720218 in Mayport, Florida (NOAA 2018a), and weather data from the NOAA weather station (Mayport, station USW00003853, and the Fernandina Beach Airport, station US1FLNS0014) nearest each site. In April to mid-July 2015, we used data from the Fernandina Beach station (US1FLNS0012) instead of the Fernandina Beach Airport station because data from the latter were not available. The tide station was 3-21 km from each site, the Mayport weather station was $3-5 \mathrm{~km}$ from the southern sites, and the Fernandina Beach and Fernandina Beach Airport station were 8-16 km and 3-11 km from the northern sites, respectively. We determined distance to upland edge by calculating the distance from the nest site to the nearest boundary for a land cover class that was not salt marsh or open water using the Florida Cooperative Land Cover Map (Version 3.2, October 2016; FFWCC \& FNAI 2016). We obtained the elevation at each nest using LIDAR data (University of Florida GeoPlan Center 2013). 


\subsection{Analysis}

We used logistic exposure models to estimate daily nest survival while controlling for varying nest check intervals (Shaffer 2004). We used the R programing environment and the 'glm' function with a custom link function per Shaffer (2004) to fit models (R Development Core Team 2017). We treated nests with temperature loggers as being checked daily in our nest survival analysis. We used the day's highest high tide and rainfall total for nests that had a nest check interval of $1 \mathrm{~d}$, and the maximum high tide and maximum daily rainfall total across all days when the nest check interval was $>1 \mathrm{~d}$.

We assigned a nest stage (lay, incubation, nestling) to each nest check interval based on the nest contents. We used laying dates to help age nests when possible but collapsed the laying and incubation stages into an 'eggs' stage for the analysis because we could not distinguish between these 2 stages if a nest failed during the first nest check interval since it was often unclear whether the clutch observed at discovery was complete. We assigned the final nest stage as 'eggs' for any nest with eggs that were incubated $<12 \mathrm{~d}$. When possible, we used data from the temperature loggers to assign daily nest stages for nests that were found during incubation and failed before we observed nestlings. For example, if logger data indicated that a sparrow nest found with a complete clutch was active for 13 total days, we assumed that failure occurred during the nestling stage because of the $11 \mathrm{~d}$ incubation period for the sparrow. We assigned a final nest stage of 'unknown' to nests found during incubation that failed before hatching unless other evidence (e.g. presence of eggshell or dead nestlings) was available. We estimated hatching dates based on nestling ages as determined by visual inspection for sparrows and an aging guide for wrens (A. Schwarzer unpubl. data) and assigned the appropriate nest stage to the daily nest check intervals from temperature loggers accordingly. We assumed that wren nestlings $\leq 9 \mathrm{~d}$ old could not have fledged, as nestlings $<10 \mathrm{~d}$ old never prematurely fledged in response to our presence. Similarly, we assumed that sparrow nestlings $\leq 6$ d old could not have fledged.

We checked covariates for multicollinearity by inspecting scatterplots and by computing the variance inflation factor (VIF) for each covariate (Fox \& Monette 1992), and assumed that a VIF $>10$ indicated that a variable could not be included in the analysis (Hair et al. 1998). VIF scores indicated that all covariates could be included in the final analysis for spar- rows, but we removed study site (VIF $=44.3$ ) from all models for wrens. We also evaluated mixed models to determine whether models with random effects of site and nest territory were better fits than models with no random effects. Using likelihood ratio tests, we compared models with and without random effects whose fixed effects consisted of the fixed effects identified via backward stepwise regression. Likelihood ratio tests indicated that, for both the sparrow and the wren, models with random effects of nest site and territory were not significantly better fits to the data when compared to models without random effects $\left(\chi^{2}=0, \mathrm{p}=1\right.$ for the sparrow; $\chi^{2}=$ $0.0459, \mathrm{p}=0.83$ for the wren). Consequently, we elected not to include random effects in our models.

We performed a 3-step model selection process that allowed us to control for temporal factors correlated with nest survival, assess the relative support for each of our a priori hypotheses, and explore the data to ensure that we were aware of the full suite of covariates correlated with nest survival. First, we evaluated the influence of temporal covariates (nest stage, year, ordinal date, and a quadratic date effect) on nest survival by assessing all combinations of the covariates using an information-theoretic approach (Burnham \& Anderson 2002). Second, we included the covariates from the top temporal model in each of the 4 models that represented our a priori hypotheses (Table 1). We ranked models using Akaike's information criterion corrected for small sample sizes $\left(\mathrm{AIC}_{\mathrm{c}}\right)$ as the information criterion, calculated model weights, and calculated for each model the difference between its weight and that of the top model. We considered any model within $4 \mathrm{AIC}_{\mathrm{c}}$ units of the top-ranked model to be competitive. Finally, we performed an exploratory analysis using backward AICbased stepwise regression (Venables \& Ripley 2002; 'stepAIC' in the 'MASS' R package) with all covariates. Stepwise regression risks identifying spurious results, but we determined it was appropriate because we sampled from (and are drawing inferences to) a substantial extent of the population of interest and because we felt, given the conservation status of the species, that it would be worse to miss important relationships than to identify spurious relationships.

Finally, based on the results from the analyses above we performed a post hoc analysis of nest survival to examine the interplay between tide levels and nest predation. For each species, we re-ran the original a priori models but limited the data analyzed to nests that either fledged or were depredated, excluding nests for which field observations indicated that the cause of failure was flooding. 


\section{RESULTS}

We found 116 sparrow nests during 2015-2017 at 4 of the 7 study sites (range: 3-83 nests site ${ }^{-1}$ ). Male sparrows defended territories at the remaining 3 sites but did not appear to be paired with females. The earliest date of nest initiation (i.e. the day the first egg is laid in a nest) was 3 April, and the breeding season was largely over by the end of July, with the last nest initiated on 3 August. The median clutch size was 3 (range $1-4, n=61)$. Fourteen nests $(12 \%$ of all nests) fledged $\geq 1$ young. Forty-five nests (39\%) were depredated, 4 (3\%) failed from flooding, and 1 $(1 \%)$ was abandoned. We could not determine the cause of failure for $47(41 \%)$ nests, and 5 nests $(4 \%)$ had unknown fates. We did not collect vegetation data at 16 nests, and these were excluded from the analysis, leaving 100 nests representing 673 exposure days.

We found 888 active wren nests (range: 11-182 nests site ${ }^{-1}$ ). The earliest nest initiation date was 13 April. Most territories were inactive by the end of July, and the latest nest initiation date we observed was 18 August. The median clutch size was 4 (range $1-6, \mathrm{n}=489)$. Of the active nests, $158(18 \%$ of all nests) fledged $\geq 1$ young. 297 nests $(33 \%)$ were depredated, $60(7 \%)$ failed from flooding, and 16 nests $(2 \%)$ were abandoned. We could not determine the cause of failure for $350(39 \%)$ nests, and 7 nests $(1 \%)$ had unknown fates. Of the 350 nests where cause of failure could not be determined, 154 did not have temperature loggers placed in them, 24 had temperature loggers that were lost, damaged, or malfunctioned, and in the remaining nests the date but not the time of failure was clear from the logger data. Thus, failure could not be matched with tide data and the physical evidence was not conclusive as to either predation or flooding. We did not collect vegetation data at 386 nests, and these were excluded from the analysis, leaving 502 nests representing 5161 exposure days.

Nest stage was the only temporal covariate selected for inclusion in the a priori models for the sparrow (Table 2). Sparrow nest survival was best predicted by the flood avoidance model, which carried the full $\mathrm{AIC}_{\mathrm{c}}$ weight (Table 1). Nest survival was positively correlated with nest height and negatively correlated with tide height (Table 2, Fig. 2). The top model identified from stepwise regression model selection for sparrows contained nest height and tide height (Table 1) but did not contain elevation, which had a negligible effect size in the flood avoidance model (Fig. 2). Coefficients in the stepwise regres-
Table 2. Parameter estimates from the top a priori and stepwise models of nest survival for seaside sparrows and marsh wrens in northeast Florida, USA, 2015-2017

\begin{tabular}{|c|c|c|c|c|}
\hline Covariate & Estimate & SE & $z$-value & $\mathrm{p}$ \\
\hline \multicolumn{5}{|c|}{ Seaside sparrow top a priori (flood avoidance) model } \\
\hline Intercept & 6.852 & 1.698 & 4.0 & $<0.001$ \\
\hline Nestling stage & 0.755 & 0.322 & 2.3 & 0.019 \\
\hline Unknown stage & -1.077 & 0.314 & -3.4 & 0.001 \\
\hline Nest height & 2.086 & 0.997 & 2.1 & 0.036 \\
\hline Elevation & 0.219 & 0.657 & 0.3 & 0.739 \\
\hline Tide & -3.670 & 0.914 & -4.0 & $<0.001$ \\
\hline \multicolumn{5}{|c|}{ Seaside sparrow stepwise model } \\
\hline Intercept & 7.110 & 1.519 & 4.7 & $<0.001$ \\
\hline Nestling stage & 0.755 & 0.322 & 2.3 & 0.019 \\
\hline Unknown stage & -1.082 & 0.314 & -3.4 & 0.001 \\
\hline Nest height & 1.908 & 0.849 & 2.2 & 0.025 \\
\hline Tide & -3.690 & 0.912 & -4.1 & $<0.001$ \\
\hline \multicolumn{5}{|c|}{ Marsh wren top a priori (flood avoidance) model } \\
\hline Intercept & 8.307 & 0.836 & 9.9 & $<0.001$ \\
\hline Nestling stage & 0.448 & 0.136 & 3.3 & 0.001 \\
\hline Unknown stage & -2.351 & 0.177 & -13.3 & $<0.001$ \\
\hline Year (2016) & 0.307 & 0.135 & 2.3 & 0.023 \\
\hline Year (2017) & 0.406 & 0.175 & 2.3 & 0.020 \\
\hline Nest height & 0.494 & 0.415 & 1.2 & 0.234 \\
\hline Elevation & -0.621 & 0.208 & -3.0 & 0.003 \\
\hline Tide & -3.751 & 0.439 & -8.6 & $<0.001$ \\
\hline \multicolumn{5}{|c|}{ Marsh wren stepwise model } \\
\hline Intercept & 8.820 & 0.775 & 11.4 & $<0.001$ \\
\hline Nestling stage & 0.431 & 0.141 & 3.1 & 0.002 \\
\hline Unknown stage & -2.374 & 0.182 & -13.1 & $<0.001$ \\
\hline Year (2016) & 0.334 & 0.136 & 2.4 & 0.014 \\
\hline Year (2017) & 0.479 & 0.171 & 2.8 & 0.005 \\
\hline Needlerush at nest & -0.014 & 0.008 & -1.8 & 0.077 \\
\hline Needlerush $(50 \mathrm{~m})$ & -0.023 & 0.008 & -3.1 & 0.002 \\
\hline Concealment & 0.005 & 0.002 & 2.1 & 0.034 \\
\hline Short cordgrass $(50 \mathrm{~m})$ & -0.012 & 0.003 & -4.0 & $<0.001$ \\
\hline Elevation & -0.467 & 0.217 & -2.2 & 0.032 \\
\hline Precipitation & -0.125 & 0.038 & -3.3 & 0.001 \\
\hline Tide & -3.699 & 0.447 & -8.3 & $<0.001$ \\
\hline
\end{tabular}

sion model were similar to those in the flood avoidance model (Table 2). The overall probability that a sparrow nest would survive from laying to fledging young was 0.03 (95\% CI: 0.00, 0.10). Modeling nest survival as a function of tide levels revealed frequent tidal events that resulted in extraordinarily low rates of nest survival for nesting sparrows (Fig. 3).

The post hoc dataset for sparrows that excluded nests that failed from flooding included 53 nests representing 400 exposure days. The flood avoidance model $\left(\mathrm{AIC}_{\mathrm{c}}=195.19 ; W_{\mathrm{i}}=0.18\right)$ ranked higher than the null hypothesis $\left(\mathrm{AIC}_{\mathrm{c}}=196.61 ; w_{\mathrm{i}}=0.09\right)$ and the tide covariate was still supported $\left(\beta_{\text {tide }}=-3.39 \pm 1.38\right.$ $\mathrm{SE}, \mathrm{p}=0.01)$. The nest scale predation model $\left(\mathrm{AIC}_{\mathrm{c}}=\right.$ 192.58; $w_{\mathrm{i}}=0.68$ ) had the most weight, and no other model ranked above the null or had $>0.03$ of the over- 

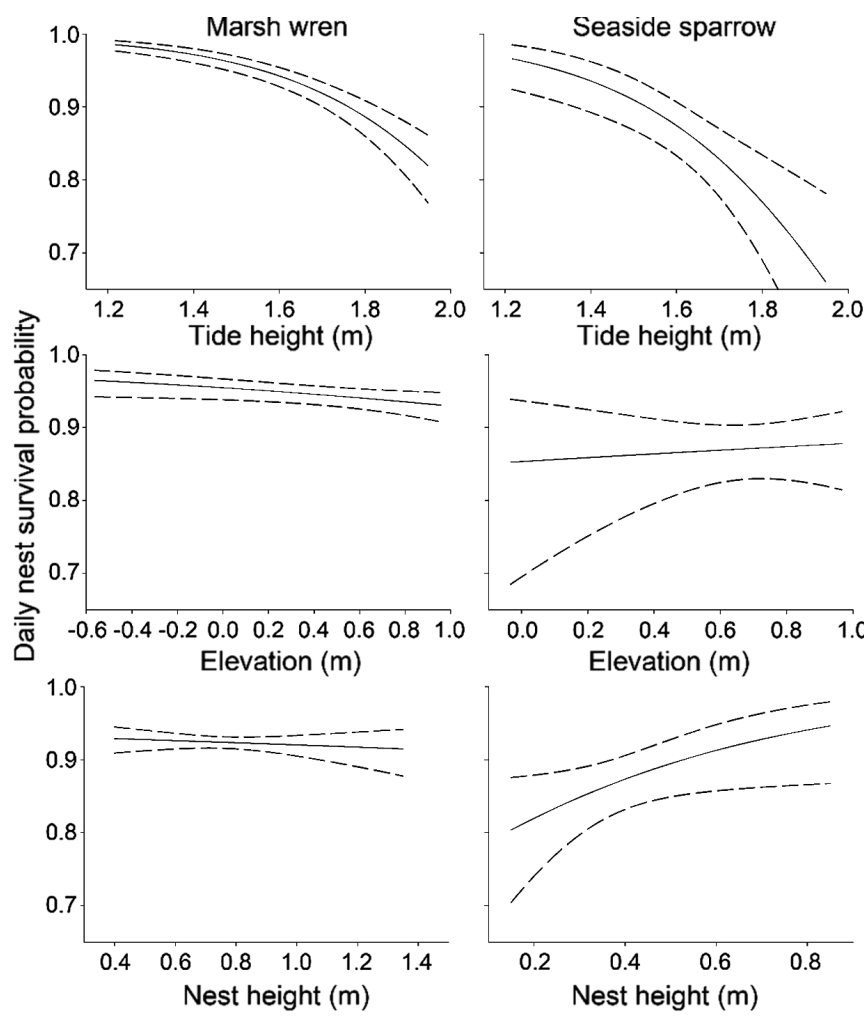

Fig. 2. Daily nest survival as a function of the covariates in the top a priori model for marsh wrens and seaside sparrows in northeast Florida, USA, during 2015-2017. Daily survival is plotted across the observed range of values for each covariate. All other covariates were held at their mean values, and categorical covariates were held at their modal category. Dashed lines indicate $95 \%$ confidence intervals

all model weight. The reduction in model weight for the flood avoidance model derived from the reduced versus full dataset may in part have resulted from a reduced effect of nest height, which was no longer significant $\left(\beta_{\text {nest_height }}=1.76 \pm 1.25 \mathrm{SE}, \mathrm{p}=0.16\right)$.

Nest stage and year were the best temporal covariates for wren nest survival, with greater survival for nests in the nestling stage than during incubation, and greater survival in 2016 and 2017 than in 2015 (Table 2). The flood avoidance model of wren nest survival carried all of the $\mathrm{AIC}_{\mathrm{c}}$ weight (Table 1). Wren nest survival was negatively correlated with tide height and to a lesser extent with elevation and nest height (Fig. 2), although the standard error associated with nest height was large and the coefficient was nonsignificant. Modeling nest survival as a function of tide levels revealed frequent tidal events that resulted in extraordinarily low rates of nest survival for nesting wrens (Fig. 3).

The top model for wrens identified from stepwise regression model selection contained 2 of the 3 covariates found in the flood avoidance model (tide and
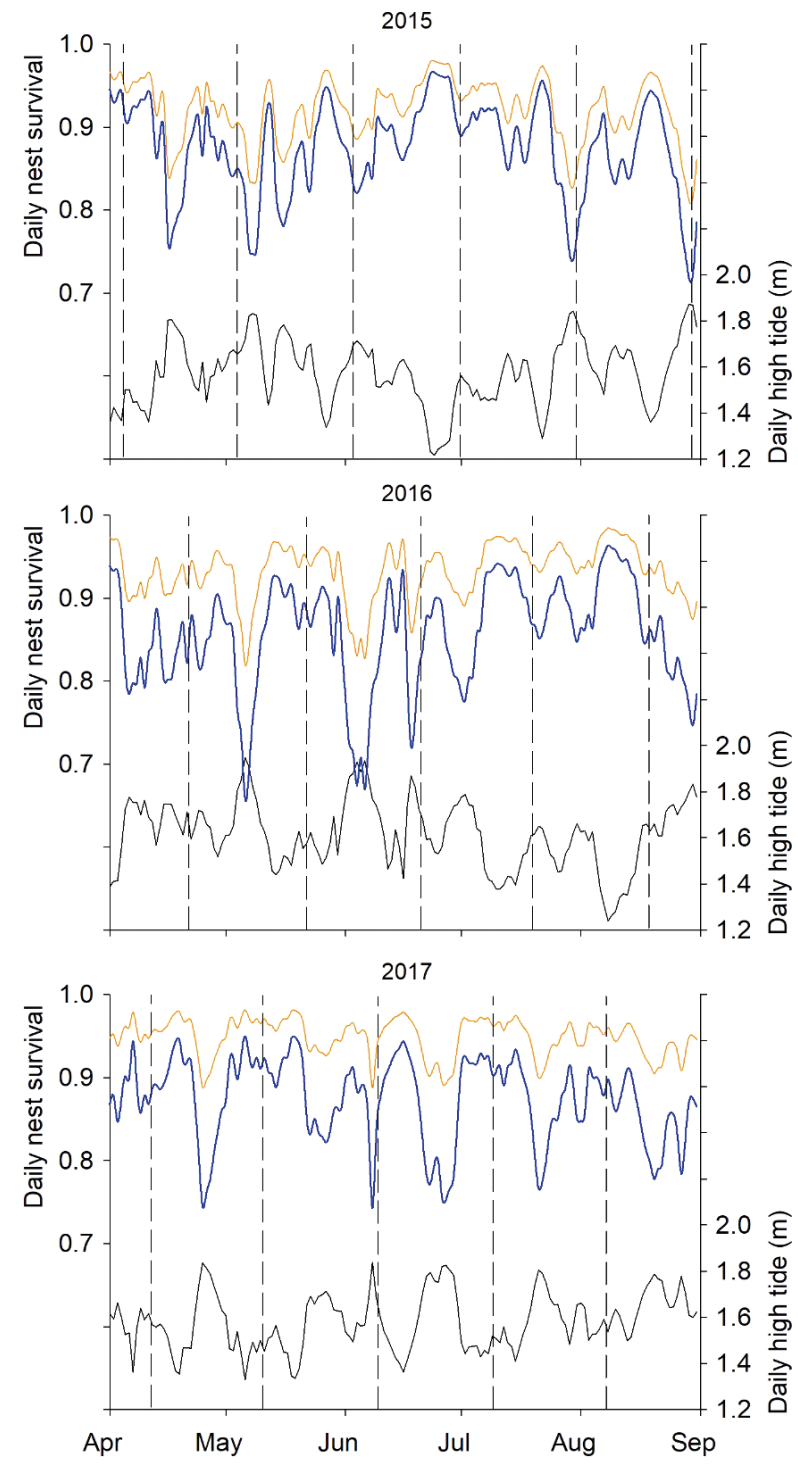

Fig. 3. Model-based predictions of daily nest survival for marsh wrens (orange lines) and seaside sparrows (blue lines) as a function of observed high tides (gray lines), 2015-2017. Predicted values are from the best stepwise model, with all other covariates held at their mean values. Vertical dashed lines indicate full moons. Few nests were initiated past 31 July

elevation but not nest height) as well as percent cover of needlerush at the nest and patch scales, mean nest concealment, precipitation, and percent cover of short cordgrass at the patch scale (Table 1). The tide and elevation parameters had similar values in the a priori and the stepwise models. Percent cover of needlerush at the nest scale and the patch scale were negatively correlated with nest survival, mean nest concealment had a very slight positive effect, precipitation had a negative effect, and percent cover of short cordgrass at the patch scale had a slight negative effect (Fig. 4). The overall probability 


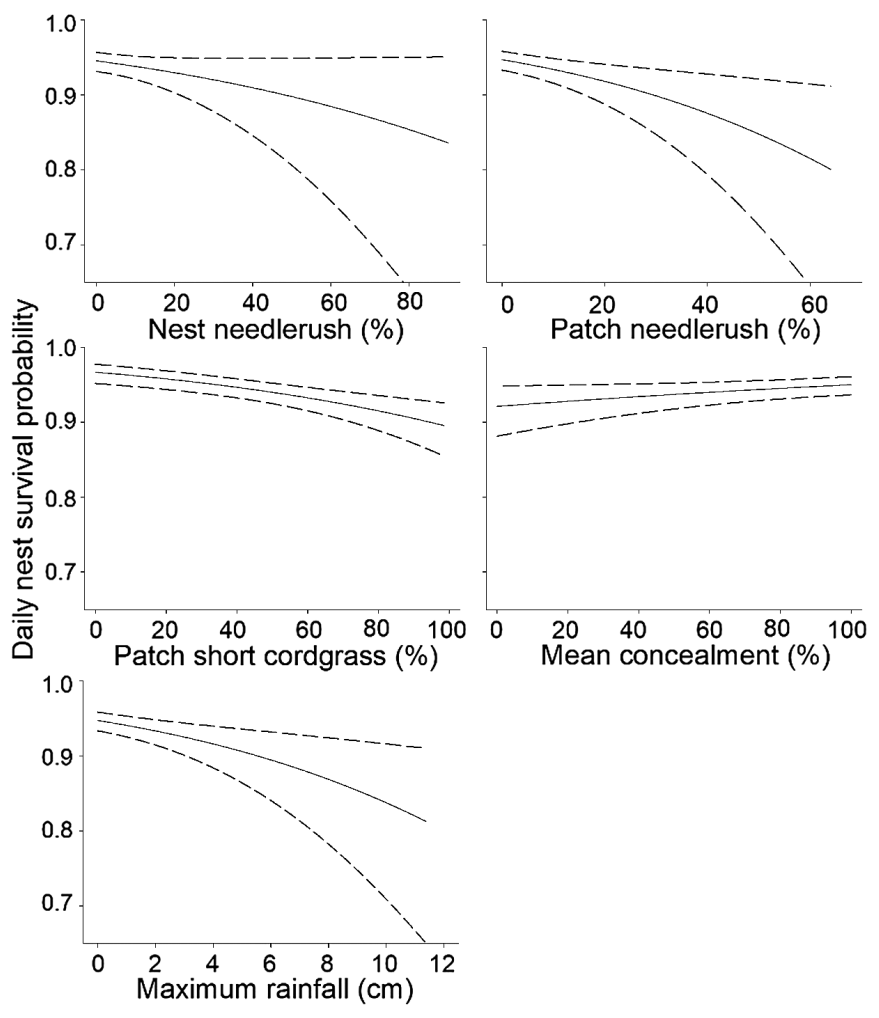

Fig. 4. Daily nest survival as a function of the covariates in the best stepwise model that were not represented in the top a priori model for marsh wrens in northeast Florida, USA, during 2015-2017. Daily survival is plotted across the observed range of values for each covariate. All other continuous covariates were held at their mean values, and categorical covariates were held at their modal category. Dashed lines indicate $95 \%$ confidence intervals

that a nest would survive the entire $27 \mathrm{~d}$ nesting period was 0.10 (95\% CI 0.04, 0.18) for wrens.

The post hoc dataset for wrens that excluded nests that failed from flooding included 284 nests representing 3443 exposure days. The flood avoidance model was the top model and carried all of the overall model weight, and the tide covariate was still supported $\left(\beta_{\text {tide }}=-3.45 \pm 0.65 \mathrm{SE}, \mathrm{p}<0.01\right)$.

\section{DISCUSSION}

Obligate salt marsh species occupy a narrow band of transitional habitat between marine and upland environments and can be exposed to stressors originating in either. Our results indicate that the overwhelming threat to wren and sparrow productivity comes from greater than normal high tides (i.e. spring tides and other higher than predicted tidal events in a monthly tidal cycle) rather than from features within the salt marsh or from proximity to upland habitat. Salt marsh birds tend to have small clutches (Greenberg et al. 2006) and can have rapid re-nesting rates (Gjerdrum et al. 2005) to accommodate a typical 29 d tidal cycle. Breeding often becomes synchronized with the tidal cycle, minimizing the risk of nest loss from flooding because young can fledge between spring tides (Marshall \& Reinert 1990). In our study, the effect of tide height was substantial for both species, and modeling daily nest survival as a function of tides suggests that birds had few time periods during which nest survival would have been relatively high for the duration of a nest attempt (Fig. 3). Data from another salt marsh obligate species (the saltmarsh sparrow Ammospiza caudacuta) suggest that the loss of such lower-risk time periods can quickly lead to demographic collapse (Field et al. 2017).

It is possible that the nest survival rates we observed were artificially low as a function of our repeat visits to nests, which in some places created narrow, depressed pathways through the marsh. We think this is unlikely because the temporal patterns of nest survival we observed (i.e. greater nest survival in the nestling versus the incubation stage even though most nests were found during laying or early incubation, no seasonal change in nest survival) do not suggest an accumulating risk of predation associated with our repeated visits to nests and territories.

If unbiased, the nest survival rates we observed may be insufficient to support a stable population. However, nest survival for wrens was greater in the latter 2 years of our study than in 2015 (Table 2), year effects for sparrows can be pronounced (Hunter et al. 2016), and adults need not be reproductively successful each year if adult survival is relatively high. Unfortunately, we do not have adult survival data from our sites for either species, nor do we have data for marsh wrens from any coastal site. There is evidence that adult survival for sparrows can be relatively high for a songbird; annual adult survival was $72-90 \%$ for a migratory population in Connecticut (Borowske 2015), $86 \%$ for a small sample of nonmigratory males in Florida (Post et al. 1983), and 88\% for another population of nonmigratory males in Florida (Werner 1975). However, other studies suggest that survivorship for seaside and saltmarsh sparrows can be substantially lower (62\%, Roberts et al. 2017; 52-57\%, Field et al. 2018). More data are needed from our study area to better contextualize our nest survival results.

Unfortunately, wrens appeared to have few behavioral options available with which to respond to the threat of high tides, as nests at higher elevations and 
at greater heights did not exhibit greater nest survival (surprisingly, there was a slightly negative relationship between elevation and nest survival). Contrary to our prediction, sparrow nest survival did improve with increasing nest height, which suggests that birds may adjust their breeding strategies by building higher nests in response to initial nest failure from high tides (e.g. Gjerdrum et al. 2005, Hunter et al. 2016) without a concomitant increase in risk of failure from predation. There is some support for this idea from our post hoc analysis, as nest height was a significant predictor of overall nest survival in the original analysis but was not a significant predictor of predation risk when derived from the reduced dataset. It is not clear why our observations differ from other research, but it may in part be because nest predation is primarily due to terrestrial marsh rice rats (Post et al. 1983) rather than aerial predators that might detect higher nests with greater frequency. Regardless, the exceptionally low nest survival we observed suggests it is unlikely that the behavioral plasticity of the species is sufficient to fully mitigate the challenge of high tides.

Assigning cause-specific fates to failed songbird nests can be challenging in the absence of visual evidence, but we only infrequently encountered physical evidence of nest loss via flooding (e.g. soggy or missing nests and bent vegetation nearby), and nest temperature data indicated that comparatively few nests failed within $1.5 \mathrm{~h}$ on either side of a high tide. In addition, our post hoc analyses for both species indicated that predation risk (rather than overall risk) was positively correlated with tide height; the flood avoidance model carried all the weight for marsh wrens and had more weight than a null model for sparrows, and the beta for tide height was negative and statistically significant for both species. High tides likely have direct and indirect effects that contribute to increased rates of nest failure. For example, we often observed wrens and sparrows foraging in lower-elevation, short cordgrass-dominated flats during lower tides and retreating to nesting territories during higher tides. Nest predators such as marsh rice rats, American mink Neovison vison, and terrestrial snakes may exhibit similar strategies, concentrating during high tides near or in higher elevation areas along creek sides where wrens and sparrows frequently nested. In addition, we often observed marsh rice rats, crabs (family Sesarmidae, likely Armases and/or Sesarma spp.), and insects, including native ants, in wren nests, which suggests they may act as refugia during high tides. Regardless of the mechanism, for both species the low rate of nest survival during incubation compared with the nestling period (Table 2) suggests that nests vulnerable to failure fail quickly.

Sea-level rise associated with climate change is expected to profoundly affect Florida's coastal habitats and species (Stys et al. 2017), including salt marsh and salt marsh obligates. Salt marsh in some regions of Florida may see an increase in extent following sea-level rise (Geselbracht et al. 2015), and in general salt marsh may be able to accrete at a rate sufficient to outpace sea-level rise (Morris et al. 2002, Kirwan et al. 2016). However, many salt marshes require upland migration concomitant with accretion to be resilient to sea-level rise (Kirwan et al. 2016), which is not likely to be possible in northeast Florida, where so much of the upland has been developed. Furthermore, most modeling has not acknowledged habitat preferences of birds across the minor but important salinity and elevation gradients that define salt marshes. The most relevant work to date was completed by Hunter (2017), who demonstrated that overall marsh extent can be a misleading indicator of actual habitat availability for salt marsh birds. Her modeling predicted that most of the high-elevation marsh on which seaside sparrows depend in Georgia will transition by 2100 to low-elevation marsh that is unsuitable for the species. Sea levels in northeast Florida have risen $>12 \mathrm{~cm}$ since 1950 (NOAA 2018b), and this transition from high to low marsh may have already begun.

Our stepwise model for sparrows was nested within the top-ranked a priori model, indicating that the stepwise procedure did not detect additional factors influencing nest survival for the species. In contrast, the best stepwise model for wrens included additional covariates not in the top ranked a priori model that were associated with nest survival (Table 1). For example, the proportion of the patch and nest vegetation that was needlerush appeared to reduce nest survival. The confidence intervals around both estimates are wide, but these results are consistent with our observations in the field, where nearly all nests in needlerush-dominated habitats failed almost immediately. The results are also consistent with our assumption that marsh rice rats, which prefer needlerush over cordgrass (Post 1981), are the primary nest predator in southeastern salt marshes (Kale 1965, Post et al. 1983), but photo or video data are needed for confirmation.

The remaining covariates in the stepwise model for wrens were precipitation, nest concealment, and patch-level short cordgrass. Increased precipitation was associated with decreased nest survival, which was consistent with our predictions. Spring and sum- 
mer storms in Florida can produce substantial rain within an hour, and it is plausible that the storms might directly cause nests to fail due to structural collapse of the nest ball. In addition, inflow into the systems from heavy rain may exacerbate the tidal effects we describe above, although the effect of precipitation was not seen in sparrows. The positive relationship between nest concealment and survival is consistent with the frequently tested hypothesis that nests in dense foliage fare better than those that are more exposed (reviewed by Borgmann \& Conway 2015) and suggests that marsh rice rats and other nest predators rely in part on visual cues to locate nests. It is less clear why increased short cordgrass in the nest patch was associated with decreased nest survival. We did not include the covariate in our a priori patch-level nest predation hypothesis because we thought it might be collinear with the amount of tall cordgrass in the patch (i.e. more tall cordgrass would necessarily equate with less short cordgrass) and because we could not hypothesize a mechanism linking short cordgrass to nest survival. Short cordgrass was not ultimately collinearly related with tall cordgrass, but we cannot offer explanations for this relationship that are not overly reliant on conjecture, and feel the relationship merits further study.

\section{CONCLUSIONS}

Northeast Florida's remaining high-elevation, cordgrass-dominated salt marshes hold the state's only populations of MacGillivray's seaside sparrows and Worthington's marsh wrens. Protection of the marshes, and research that identifies ways to maintain and/or create cordgrass-dominated habitat, should be priorities. The future of northeast Florida's salt marshes in the face of continued sea-level rise may rely on climate-adaptive management. Wigand et al. (2017) identified 3 broad climate-adaptive approaches (improving resistance, increasing resilience, and enabling transition) that comprise 5 management foci: (1) shoreline protection via installation of living shorelines; (2) increase in marsh elevations via thin-layer application of dredged sediments; (3) restoration of marsh drainage via creation of creeks and ponds; (4) facilitation of upland marsh migration via removal of barriers to migration; and (5) restoration of sediment delivery via removal of inland dams. Not all of those actions are realistic for northeast Florida, but a structured, data-centered approach to identifying where and when to apply these restoration activities is warranted.
Acknowledgements. Funding for this study was provided by Florida's State Wildlife Grant program (grant F14AF00892 [T-35] and the Non-Game Trust Fund. We thank J. Brisbane, S. Jeffreys, L. Mengak, R. Rhodes, and L. Evans for their help in the field, and B. Bankovich for assistance with GIS. R. Boughton, A. S. Cox, B. Crowder, K. Miller, and L. Brown provided feedback that greatly improved the manuscript. All applicable ethical guidelines for the use of birds in research were followed, including those presented in the Ornithological Council's Guidelines to the Use of Wild Birds in Research. Capture and banding of birds was authorized under permit no. 21980 issued by the US Fish and Wildlife Service's Bird Banding Laboratory.

\section{LITERATURE CITED}

Bayard TS, Elphick C (2011) Planning for sea-level rise: quantifying patterns of saltmarsh sparrow (Ammodramus caudacutus) nest flooding under current sea-level conditions. Auk 128:393-403

* Borgmann KL, Conway CJ (2015) The nest-concealment hypothesis: new insights from a comparative analysis. Wilson J Ornithol 127:646-660

Borowske A (2015) Effects of life history strategies on annual events and processes in the lives of tidal marsh sparrows. PhD dissertation, University of Connecticut, Storrs, CT

Burnham KP, Anderson DR (2002) Model selection and multimodel inference: a practical information-theoretic approach. Springer, New York, NY

Cavanaugh KC, Kellner JR, Forde AJ, Gruner DS, Parker JD, Rodriguez W, Feller IC (2014) Poleward expansion of mangroves is a threshold response to decreased frequency of extreme cold events. Proc Natl Acad Sci USA 111:723-727

Chicalo RM, Schwarzer AS, Cox WA (2019) Observations on the use of dummy nests by fledgling Worthington's marsh wrens (Cistothorus palustris griseus). Wilson J Ornithol 131:396-398

* Donnelly JP, Bertness MD (2001) Rapid shorebird encroachment of salt marsh cordgrass in response to accelerated sea-level rise. Proc Natl Acad Sci USA 98:14218-14223

Donovan TM, Thompson FR III (2001) Modeling the ecological trap hypothesis: a habitat and demographic analysis for migrant songbirds. Ecol Appl 11:871-882

Field CR, Bayard TS, Gjerdrum C, Hill JM, Meiman S, Elphick CS (2017) High-resolution tide projections reveal extinction threshold in response to sea-level rise. Glob Change Biol 23:2058-2070

Field CR, Ruskin KJ, Benvenuti B, Borowske A and others (2018) Quantifying the importance of geographic replication and representativeness when estimating demographic rates using a coastal species as a case study. Ecography 41:971-981

Fletcher RJ Jr, Koford RR, Seaman DA (2006) Critical demographic parameters for declining songbirds breeding in restored grasslands. J Wildl Manag 70:145-157

FFWCC (Florida Fish and Wildlife Conservation Commission) (2012) Florida's wildlife legacy initiative: Florida's state wildlife action plan. FFWCC, Tallahassee, FL

FFWCC (2016) Florida's imperiled species management plan. FFWCC, Tallahassee, FL

FFWCC, Florida Natural Areas Inventory (FNAI) (2016) Cooperative land cover version 3.2 vector. FFWCC, Tallahassee, FL

Fox J, Monette G (1992) Generalized collinearity diagnostics. J Am Stat Assoc 87:178-183 
Geselbracht LL, Freeman K, Birch AP, Brenner J, Gordon DR (2015) Modeled sea level rise impacts on coastal ecosystems at six major estuaries on Florida's gulf coast: implications for adaptation planning. PLOS ONE 10: e0132079

KGerdrum C, Elphick CS, Rubega M (2005) Nest site selection and nesting success in salt marsh breeding sparrows: the importance of nest habitat, timing, and study site differences. Condor 107:849-862

Greenberg R, Maldonado JE (2006) Diversity and endemism in tidal-marsh vertebrates. In: Greenberg R, Maldonado JE, Droege S, McDonald MV (eds) Studies in avian biology 32. Terrestrial vertebrates of tidal marshes: evolution, ecology, and conservation. Cooper Ornithological Society, Ephrata, PA, p 32-53

Greenberg R, Elphick C, Nordby CJ, Gjerdrum C and others (2006) Flooding and predation: trade-offs in the nesting ecology of tidal-marsh sparrows. In: Greenberg R, Maldonado JE, Droege S, McDonald MV (eds) Studies in avian biology 32 . Terrestrial vertebrates of tidal marshes: evolution, ecology, and conservation. Cooper Ornithological Society, Ephrata, PA, p 96-109

Hair JF Jr, Anderson RE, Tatham RL, Black WC (1998) Multivariate data analysis. Prentice-Hall, Englewood Cliffs, NJ

Hunter EA (2017) How will sea-level rise affect threats to nesting success for seaside sparrows? Condor 119:459-468

*Hunter EA, Nibbelink NP, Cooper RJ (2016) Threat predictability influences seaside sparrow nest site selection when facing trade-offs from predation and flooding. Anim Behav 120:135-142

Hunter EA, Nibbelink NP, Cooper RJ (2017) Divergent forecasts for two salt marsh specialists in response to sea level rise. Anim Conserv 20:20-28

Kale HW II (1965) Ecology and bioenergetics of the longbilled marsh wren Telmatodytes palustris griseus (Brewster) in Georgia salt marshes. Publ Nuttall Ornithol Club 5. Nuttall Ornithology Club, Cambridge, MA

Kale HW II (1996a) Marsh wrens. In: Rodgers JA Jr, Kale HW II, Smith HT (eds) Rare and endangered biota of Florida. University Press of Florida, Gainesville, FL, p 602-607

Kale HW II (1996b) Seaside sparrows. In: Rodgers JA Jr, Kale HW II, Smith HT (eds) Rare and endangered biota of Florida. University Press of Florida, Gainesville, FL, p 608-615

Kern RA, Shriver WG, Bowman JL, Mitchell LR, Bounds DL (2012) Seaside sparrow reproductive success in relation to prescribed fire. J Wildl Manag 76:932-939

Kirwan ML, Temmerman S, Skeehan EE, Guntenspergen GR, Fagherazzi S (2016) Overestimation of marsh vulnerability to sea level rise. Nat Clim Chang 6:253-260

Kroodsma DE, Verner J (2013) Marsh wren (Cistothorus palustris), version 2.0. In: Poole AF (ed) The birds of North America, Cornell Lab of Ornithology, Ithaca, NY

Leonard ML, Picman J (1987) Nesting mortality and habitat selection by marsh wrens. Auk 104:491-495

Marshall RM, Reinert SE (1990) Breeding ecology of seaside sparrows in a Massachusetts salt marsh. Wilson Bull 102: 501-513

Martin TE (1992) Breeding productivity considerations: What are the appropriate habitat features for management? In: Hagan JM III, Johnston DW (eds) Ecology and conservation of neotropical migrant landbirds. Smithsonian Institution Press, Washington, DC, p 455-473

Martin TE, Geupel GR (1993) Nest-monitoring plots: methods for locating nests and monitoring success. J Field Ornithol 64:507-519
Morris JT, Sundareshwar PV, Nietch CT, Kjerfve B, Cahoon DR (2002) Responses of coastal wetlands to rising sea level. Ecology 83:2869-2877

NOAA (National Oceanic and Atmospheric Administration) (2018a) Tides and currents. https://tidesandcurrents. noaa.gov (accessed 8 May 2018)

NOAA (2018b) National centers for environmental information climate data online search. https://www.ncdc.noaa. gov/cdo-web/search (accessed 1 October 2017)

Nuse BL, Cooper RJ, Hunter EA (2015) Prospects for predicting changes to coastal wetland bird populations due to accelerated sea level rise. Ecosphere 6:286

* Post W (1981) The influence of rice rats Oryzomys palustris on the habitat use of the seaside sparrow Ammospiza maritima. Behav Ecol Sociobiol 9:35-40

* Post W, Greenlaw JS (2018) Seaside sparrow (Ammospiza maritima), version 2.1. In: Rodewald PG (ed) The birds of North America. Cornell Lab of Ornithology, Ithaca, NY

* Post W, Greenlaw JS, Merriam TL, Wood LA (1983) Comparative ecology of northern and southern populations of the seaside sparrow. In: Quay TL, Funderburg JB Jr, Lee DS, Potter EF, Robbins CS (eds) The seaside sparrow, its biology and management. Occasional Papers of the North Carolina Biological Survey. NCBS, Raleigh, NC, p 123-136

R Development Core Team (2017) R: a language and environment for statistical computing. R Foundation for Statistical Computing, Vienna

*Roberts SG, Longenecker RA, Etterson MA, Ruskin KJ, Elphick CS, Olsen BJ, Shriver WG (2017) Factors that influence vital rates of seaside and salt marsh sparrows in coastal New Jersey, USA. J Field Ornithol 88: $115-131$

Shaffer TL (2004) A unified approach to analyzing nest success. Auk 121:526-540

Stys B, Foster T, Fuentes MMPB, Glazer B, Karish K, Montero N, Reece JS (2017) Climate change impacts on Florida's biodiversity and ecology. In: Chassignet EP, Jones JW, Misra V, Obeysekera J (eds) Florida's climate. Florida Climate Institute, Gainesville, FL, p 339-389

Sutti F, Strong AM (2014) Temperature loggers decrease costs of determining bird nest survival. Wildl Soc Bull 38: 831-836

University of Florida GeoPlan Center (2013) FLIDAR mosaic source areas and known gaps. University of Florida GeoPlan Center, Gainesville, FL

USFWS (United States Fish and Wildlife Service) (2018) Species status assessment report for the MacGillivray's seaside sparrow (Ammodramus maritimus macgillivraii) Version 1.3. USFWS, Atlanta, GA

Venables WN, Ripley BD (2002) Modern applied statistics with S, 4th edn. Springer, New York, NY

*Verner J, Engelsen GH (1970) Territories, multiple nest building, and polygyny in the long-billed marsh wren. Auk 87:557-567

Werner HW (1975) The biology of the Cape Sable seaside sparrow. US Fish and Wildlife Service, US Department of the Interior, Everglades National Park, Homestead, FL

*Wigand C, Ardito T, Chaffee C, Ferguson W and others (2017) A climate change adaptation strategy for management of coastal marsh systems. Estuaries Coasts 40: 682-693

*Williams AA, Eastman SF, Eash-Loucks WE, Kimball ME, Lehmann ML, Parker JD (2014) Record northernmost endemic mangroves on the United States Atlantic coast with a note on latitudinal migration. Southeast Nat 13: 56-63

Submitted: May 2, 2019; Accepted: December 11, 2019

Proofs received from author(s): January 24, 2020 